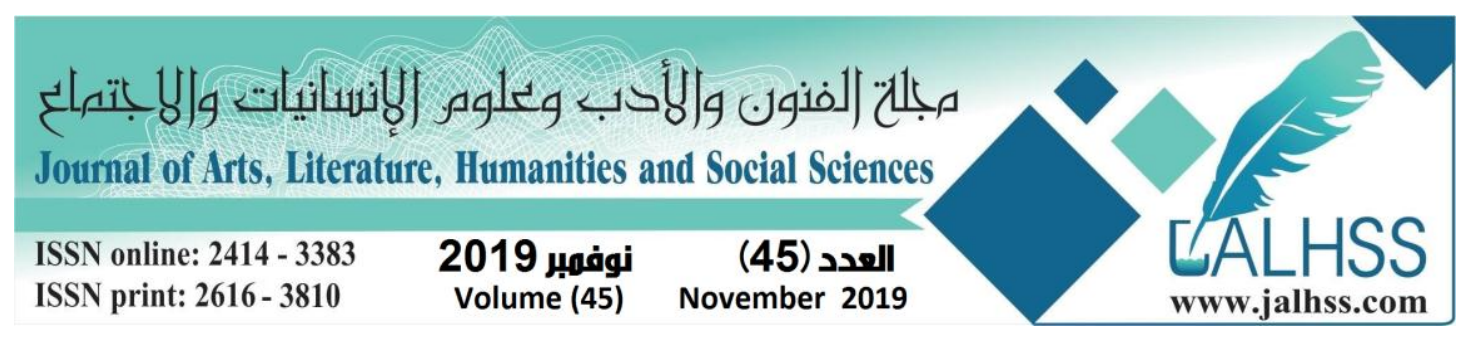

\title{
Meaning and Truth Means in the Kurdish
}

\author{
Fareeq Ghazi Awla \\ Belgorod State University -Institute of Cross-Cultural Communications and \\ International Relations - Theory of languages
}

\begin{abstract}
The objective of this study is to examine the phenomenon of ideals in the linguistic and cultural aspect, based on a comparative study of the representation of the concept of "truth / Alrasta" in Proverbs in the Kurdish language and the analysis of the similarities and differences in the characteristics of the national way of thinking. The aim of the research is Kurdish proverbs for the truth. Research topic: is the stereotype of the concept of cultural ideals "truth Alrasta" national privacy and to represent them in the semantics of Kurdish proverbs, to achieve this goal, was completed the following tasks:

1. Theoretical study of materials on the subject of research.

2. Analysis of proverbs that reflect the concept of "Rasti" in Kurdish.

Work structure includes an introduction and a chapter theoretical and practical chapters and a conclusion and a list of references.

The work used Kurdish dictionaries for proverbs and linguistic units. Sampling methods we used continuous sampling, analysis of vocabulary definitions, conceptual analysis, quantitative calculation, comparison method, equivalent translation.

Reasons for the selection thread is to choosing this topic because of the importance of the subject of the Kurdish reality of the Kurdish and the other hand Please choose a because of the need to identify the similarities and differences in language pictures of the world, registered in the Kurdish language with other GATT on the basis of popular proverbs.
\end{abstract}




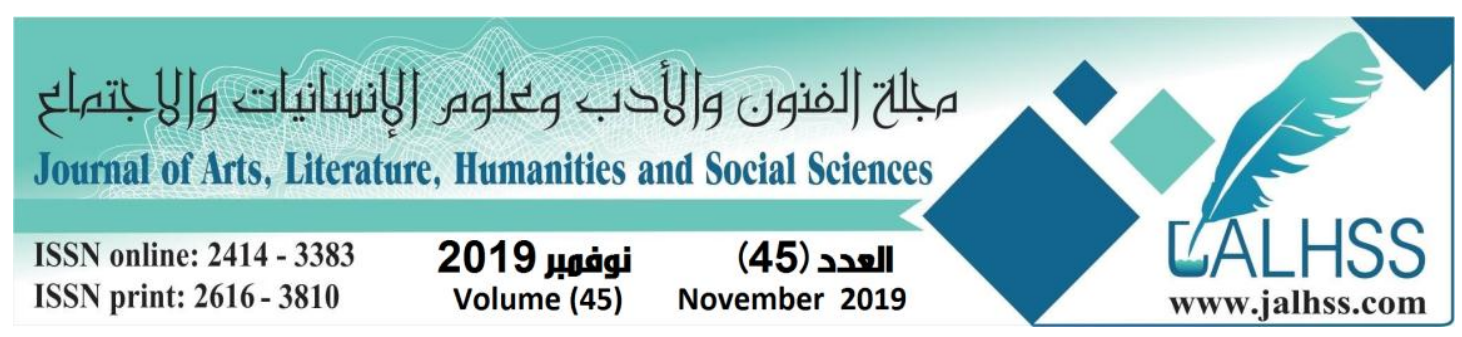

\section{Introduction:}

The words of wisdom for the ancient in the eyes and thought of writers, researchers and terminology have different connotations and expressions, and expressed in a variety of expressions and each one of these expressions and vision achieved part of the objectives and here we refer to a set of definitions and expressions says (Pero Rondo) in the definition of the old rule: The words of old Kurds like Latifa and joke, and this wisdom is a sentence or two short and meaningful and meaningful rhythm of music, but many of them are represented in the form of a story and a story, and this indicates that the wisdom is a short disclosure and expression but has a broad connotation of the experiences of daily life and see Others such a For experiments. These are specific to the person at this mysterious time when man is baffled to communicate his message to others as soon as possible.

Belief, justification, and truth provide models and factors that may serve as the basis for knowledge. The greatest similarity that exists between a statement and the set of existing statements within the self that represent one's beliefs is computed as the similarity between the statement and the statements that one accepts, $\mathrm{Sb}$ (statement, believed statement). It considers how empiri-cally similar information may be to existing ideas, with a high degree of similarity being indica-tive of a high degree of agreement between an existing idea and statements or perceptions.

The accuracy of a process's output is the degree of similarity between the output of the process and a normative statement or gold standard. This may be measured as the degree of agreement between an analytic or universally accepted statement and the statement being considered. Using the notion of similarity, one may compute the accuracy of a process's output as $\mathrm{Sg}$ (statement, gold standard output), where the gold standard output is the ideal, an assumed correct statement pro-duced by a process or a set of statements.

These two measures, $\mathrm{Sb}()$ and $\mathrm{Sg}()$, gauge the similarity between informative outputs from proc-esses, one with the gold standard statement and the second one with the set of statements cur-rently believed. The complement function may be used with the above similarity functions being written with the subscript c. For example, the consistency of a statement with believed statements may be denoted as $\mathrm{Sc}, \mathrm{b}($ statement $)=1-\mathrm{Sb}$ (statement, $\neg$ believed statements).

We may compute $\mathrm{Sm}, \mathrm{b}()$ as the quantitative degree of similarity between a statement and the set of believed statements, or we may compute the qualitative content $S s, b()$, the statements that are simi-lar between the statement in question and the set of believed statements.

Being very well articulated and describing the basic rules of conduct, proverbs are filled with common sense and advice. Religion, with its overwhelming influence on society and culture, played an important role in creating proverbs in the distant past. In this context, religious books such as the Bible and the Koran, as well as other divine precepts included a large number of showing that later became proverbs and should serve as a guideline as a specific set of rules of behavior for people. 


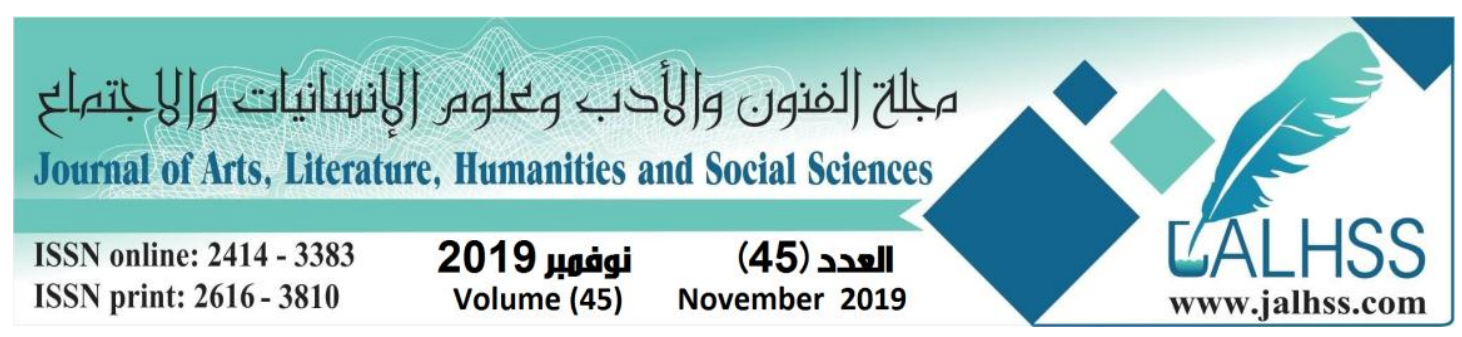

\section{What is Truth:}

Of course, the term truth in the eyes and thought of writers, researchers and terminologists have different connotations and expressions, and expressed in a variety of expressions and each of these expressions and look achieved part of the objectives and here we refer to a set of definitions and expressions says (Pero Rondo) in the definition of the old rule: The old Kurds like Latifa and joke, this wisdom sentence or two short and meaningful and meaningful rhythm of music, but many of them are represented in the form of a story and a story, and this indicates that the wisdom is a short disclosure and expression but has a broad connotation reflect the experiences of daily life and see others These experiences. These are specific to the person at this mysterious time when man is bewildered to communicate his message to others as soon as possible.(1)

Also, we can recognize the old rule as a short, pure and straight words with broad and deep connotations and is the fruit of the effort of our parents and grandparents to understand the old social life legal wisdom of the people and the community, It is noted from this definition that it focuses on the shortness of the phrase and the broad connotation, and describes the characteristics of the palace, abstract, straightness, but the level of these properties was not assigned because it cannot be the level of the tongue and the deviation of meaning on the one hand and on the other hand it says that wisdom has an ancient history but It should identify its () constraints (2) Because life is always in the tests and examinations of people and therefore achieve wisdom all the time for the continuation of life and therefore it is said that wisdom is an interesting short speech with an effective taste emerged from the heart of Amer and the attention of old people, after a strong comparison and experience and here shows us that wisdom is trying to evaluate the person and guide him to Achieves its goals.

In the definition of wisdom, Tarian says, "Old wisdom is the epitome of old thought and consideration of the future generation in the future, which reads it in different aspects of life in a thorough reading and dealing with reality. Otherwise, the quantity and how this judgment relates to the present and generations." Enter into the philosophy of life, Truth is a phrase and a word that has a broad and profound meaning and often produces a result or does not indicate a direct meaning but needs thought and thought in order to reach the intended and intended).

In this definition, it says that it is a word and this means that the seat of the writer in the word every short sentence is simple as it appears in this sentence, such as, and (Russian Focal Scholoff) that the wisdom consisted of a short light sentence easy and respond to the tongues of people in everyday life and that the sentences and words in a way It has a special musical rhythm.(3)

This view and goes to the old wisdom formed from the above and it is not heavy on the tongue at the time of expression and use and that many of them were organized under the rhyme and the weight of my hair.

The exhibits of the definitions is the definition of the ancient wisdom ie the wisdom of the old and that this presentation was by writers and linguists, but what is noticed from this definition is: that the last wisdom of the old came from the product. 


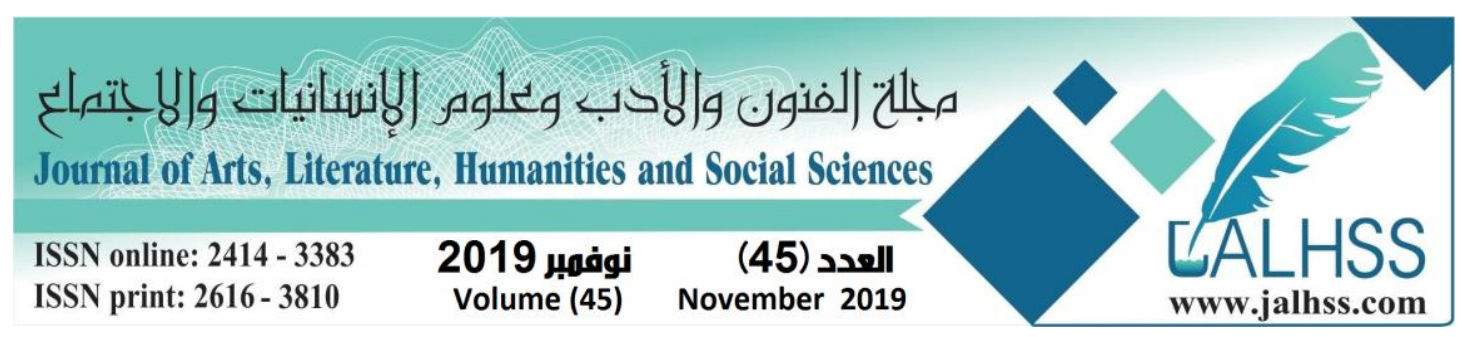

They focus on the shortness of expression and the depth of the meaning of truth so that the interpretation of its purposes can show that behind it is a story and a story.(4)

1. Many definitions are similar or similar to each other in a limited range.

2. Some of the definitions are influenced by each other.

3. The old truth is not the property of a particular individual but it belongs to all people and it is the product of society.

4. It has rhyme weight and it is easy to express and import.

\subsubsection{History and sources of Kurdish proverbs 7}

Although the Kurdish heritage topics are not collected for a number of reasons:

However, the truth was pleased in the collection, and this means a collection of books and knowledgeable in this area tried to collect the truth as a Kurdish, and yet one of the rich source of literary sources of our heritage, Because even today dozens of books have been published around them and published many publications and articles. Did not see the light of day until today this occasion that the Kurdish rule took a large area of traditional literature, before we feel so great and the sanctity of the collection and this provision before they look for them and that foreigners and those who know the Kurdish people. And they felt Alsaahin including over from its greatness and holiness.

Kurdish intellectuals then felt the first written and published interest in the lessons and the old truth in Europe in $1500 \mathrm{CE}$, which was read by the German orientalist (5) This indicates that the Orientalists were interested in the lessons and the truth, and made it in a way that I recognized, And the first manuscript in this area, which arrived to us so far this manuscript, which was written in the year 1711 titled (facilitator and what will be established) and this manuscript dozens of Kurdish truth in an Armenian version written by an unknown person.

The second manuscript is what was written in the mid-nineteenth century by (Mulla Mahmud Bayzidi, preserved in the library of the secret Lenkrad in 1878 (Ye Keizarf) in the book (Sehr Yetitiya Te'e Kra Vai Kordi) printed on the Kurds in Parvan and in the second volume, which was printed in (Tbilisi) in 1891 and dozens of Kurdish truth.(6)

In the last century, many tourists, especially Germans, went to Kurdistan, such as Prof. Ere Scarman, Von Luck Coke, and Douar Desa Khao, Tawke Setebet Rumman, and Martin Hartmann. Kurdish heritage attracted the attention of Europeans and was influenced by it, and therefore they collect and give more attention to the preservation of this national revolution of our own.

In the nineteenth century and at the beginning of the twentieth century many books were published from Armenia on the Kurdish heritage such as the world and the knowledge of the Uzbek heritage (Meshar not Taekwani) (1838-1908) had an important role in the collection of Kurdish truth, and he lived in the Kurdish areas. 


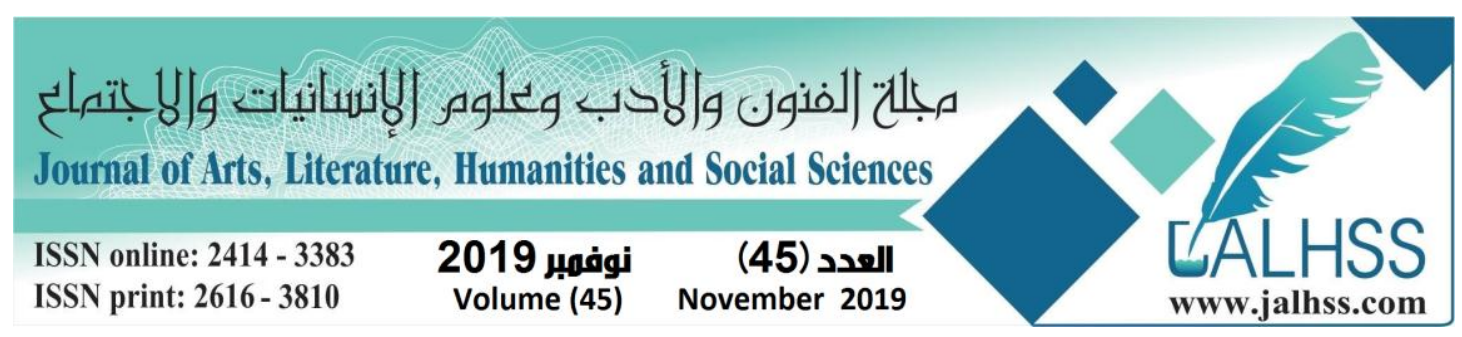

They mentioned who played a role in this field. Daduri Ramiari Einklesi (Na'el), who was a soldier in the English army in the 1920s, has a short reading about the Kurdish character and in fact the Kurds and nice words. The first to collect the Kurdish truth Almns It was written to the veterans of the Kurdish professor Ismail Hakki Shaways under the title (sayings of the old and Kostan Lebon). All of itching

زخوين وجاسمي جاليل (Zakhween, Jasmi Galil, Feh Nani Kordo and Jamila Ke Nahther) وفه ناني كوردؤ وجميله كه نه ثر

He added to those above tried forgiving Sabla to collect the Kurdish truth to survive the fear of loss and this means that the Kurds played an important role in the collection and printing of the ancient truth of the ancestors and ancient Kurds, so known known thousand truth entitled he was the first person to request that Erbil Castle be made a museum and medicine.

It is brave this field and who served the folklore of this era, which published (Zain), which collected a group of the rule of the old and the number is (6448) truth in the form of poetry and this shows that the poet (Bereh Mutaber) had a prominent role collecting Kurdish truth .(7)

In 1957, Sheikh Mohammed Khal in a book entitled (Yeh see Pichinan) collected the truth in order and interpretation by letter and printed as well, We can say that dozens of writers and intellectuals as well as those who have tried to facilitate the truth in Kurdish books and magazines little or often, but unfortunately did not print them this fact and this attempt in this area gives a new framework for our popular heritage.(8)

\section{value of truth in the Kurdish community}

Truth was born within the community and grew in it. So every one of those who speak depends on them as they speak and speak to others to strengthen their words and say we say these words as the truth said in their truth, In ancient times, truth has a special place in society, so if a person wants to strengthen his words and have an influence on others, he uses the truth.

Everyone uses them according to circumstances, place and time, such as the market, the Diwan, the hospitality, the mosques, and in the academic and political places.

There is a political and literary discourse entitled the truth is old and so the truth was a response to the tongues of people, readers, illiterates, men, women, adults and children, but unfortunately that the truth is about to forget and lose the attention of people, and declare the sunset emerging and enter the house of nothingness.

This happened after the dissemination of modern means in all areas showed a lack of interest and use by others because these means weakened social relations and this fact is the fruit of society and used in it means that there is a direct relationship between the truth and society where the stronger the relationship between the truth and grow, as published In the past our fathers and grandparents are visible, as they used the truth in their daily lives where they had in each incident the truth of its own, and whenever the society is disintegrated relations are weak and at this time we present the truth on the lack of use in people and close to loss and keep in books in libraries, looking at 


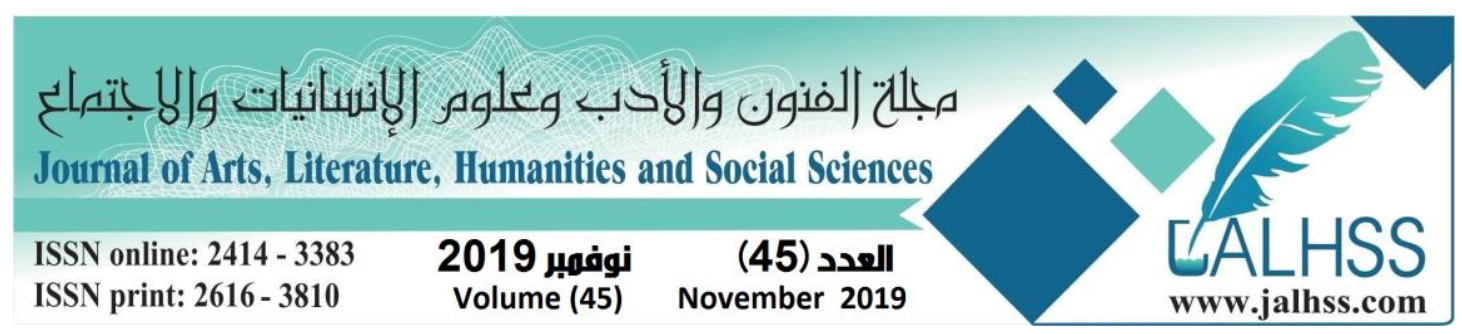

the past, people see that they were playing the role and mission of the media, and that their nightlife was adorned with the story of the story, the mystery, the songs, the truth and the sect, In the past time was the right time for the birth of truth and Nmeha but at present peoples' heritage under threat and globalization, and this evening, which was adorned in the past truth, the song and the game and the story but now people spend their time in view of television screens and mobile phones, and they sit in front of her silent so as not to happen any interference with their And their boards.(9)

\section{The content of truth}

The content of truth is the basis of truth. It is this axis which forms the core of truth and contains the purpose and meaning of truth.

Professor Alaeddin Sajjadi says in the meaning and content of truth, demonstrates how life and their behavior and beliefs both in the political and social sphere and the behavior of prisoners. Whether rich or poor, the truth presents both their earthly lives. It is clear that the truth represents different aspects of events, anecdote, circumstances, stages of life and the political and social aspect.

That is why the truth is rich in the recognition and understanding of high honors and the logical, realistic and mental view of society and that has made the truth a reason to be the content of truth is a high-standing advice provided to members of the community and in short take the content of truth from the reality of society.

"With the development of life, truth relates to different aspects, including historical, religious, social, and philosophy of life," says Izzeldin Mustafa Rasoul. Hence, it appears to us that as life progresses, Kurdish truth has an influential role in all spheres of life and community service.(9)

An example of this is: (The cities are demolished from the heart of Baghdad, although Baghdad was destroyed).This fact refers to a historical event, which is noticeable from this fact speaks of the ruin of Baghdad and this devastation is the ruin of the era of Haulage or was it another devastation and to make sure this was the responsibility of historians and linguists.

Similarly, (Muhammad's ears should be clear, visible and revealing).

This fact is related to the religious aspect and its purpose is the Islamic religion and shows the courage, pride and pride in the Islamic religion.

Split the truth of historical truth and Hakka truth by meaning and content, and then under the historical and social light, talking about the historical group, the Economic Community of belief group and about the division of truth in terms of content and meaning as follows:

1- Historical aspect:

(Egyptian sword does not stop in its sheath).

2- Economic aspect: a. Agricultural. B. Vocational and industrial.

3. Political aspect:

(If the worm is not tree-born, it is 1,000 years old.)

Be a thousand years old. 


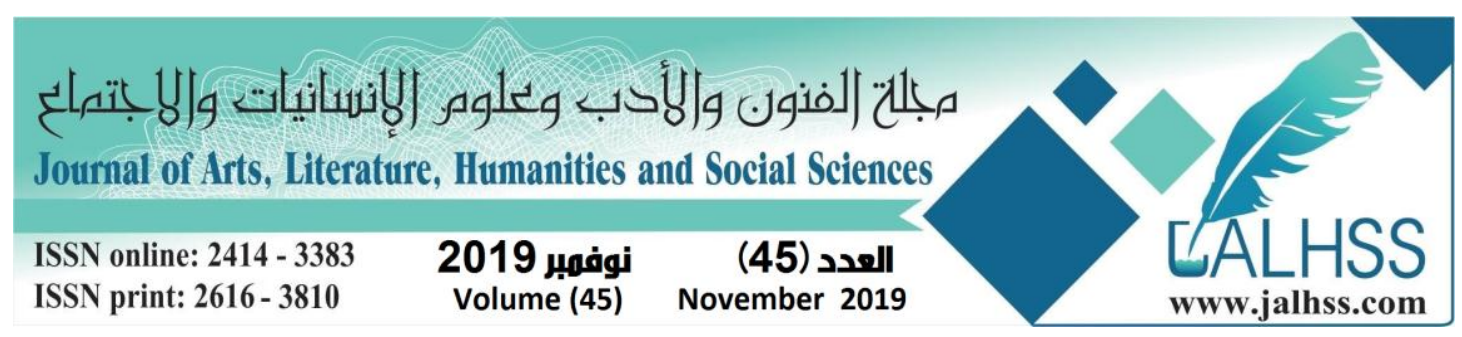

Social aspect:

equality:

(Lion emerges from the cradle, male or female)

Peace and War

(After enmity sweetness).

This means that the content of the Kurdish truth encompasses all areas of life, and we can benefit from the truth in our daily discussions, activities and life experiences and rely on what has been mentioned.

\section{Characteristics of the truth text:}

The old truth has several characteristics, and these characteristics are determined based on several sources, meaning that these characteristics differ from each other in terms of number and importance, and we show the characteristics of some of them(10)

1 - The old truth appears in the form of a brief and deep content, which means that it is a little word and deep meaning, some scientists believe that the old truth in the form of educational and advice and sermon and that few words and a lot of meaning, and from here we can say that the old truth has shown the past spread Between all segments of society and use them in their daily conversations and in general we can benefit from them in evaluating the words of the sober Kurdish.

2- Another characteristic that it contains sober Kurdish words because it was written by a simple tongue by those who said it even acted in terms of the image, but it remained as it was in terms of content and concept.

3- Another characteristic of the ancient truth shows us many useful experiences, and this truth each of which there is an experience of life.

This old fact remained from the days of our fathers and grandfathers the impact of their events and their days of joy and comfort days because of their daily work in the field of agriculture and other areas of life, All of these characteristics are similar to each other, but many researchers say that the brevity and lack of words who showed these characteristics, which are in fact the old and is intended to be brief that the words uttered few. But it has a wide and many connotations means less say and more meaning, and that keeping them easy and that transfer from generation to generation is easy and simplify does not tired in the transfer and save for brevity. It also shows in this fact (work to death) and this statement shows a broad meaning with this leave in the phrase.

\section{Conditions of Expression in the Old Truth}

In terms of content:

In fact, the truth is expressed in a variety of ways, It shows us that the old truth has characteristics and the importance that the truth that is in the form of the question is trying to get the knowledge and knowledge to fill the vacuum he feels within his brain. This fact comes in the sense of offending one another, which means that he was 


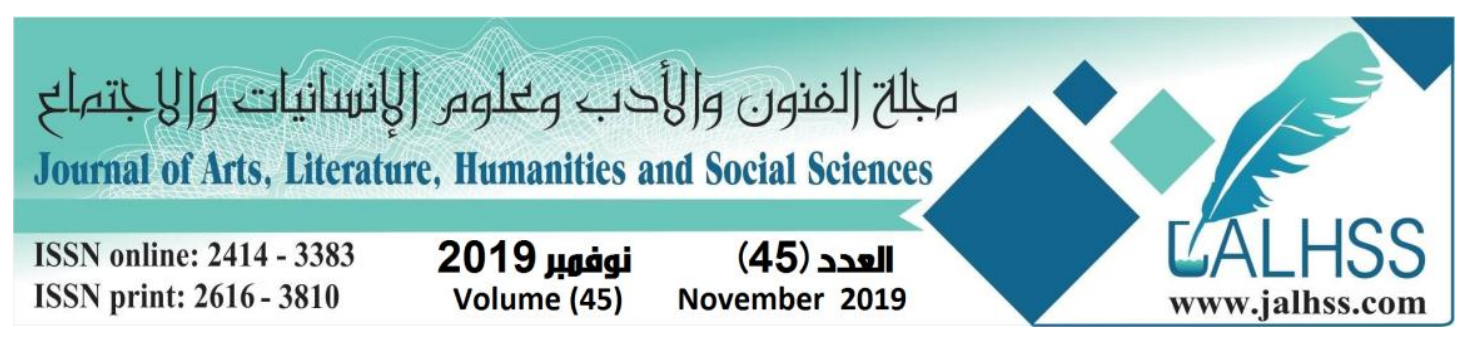

cruel with him and is now rewarding him with the same penalty and cruelty, but this is contrary to religion at all because the original replied. Abuse of charity and guidance) Do not respond to abuse and abuse in the same manner of the method of truth struggle and diligence.(11)

This fact, which is in this way, the owner tries to communicate science or knowledge to the other, but not a condition that what is delivered to the listener and the truth and truth to him because the listener and others are subject to change and not fixed on everything and every understanding such as (that the sound of the drum pleases from afar) This means that someone is famous and beneficial even though it can be useless because not everyone who is famous is good, beneficial and improved.

- style of admiration Some of the truth was revealed in the style of miracle and wonder.

- the method of the order means that some of them are or respond to the order is clearly requested to do something such as (break the stone and address the hypocrite).

This means that breaking the stone, which does not benefit the breaker and the news of him to spend his time with the hypocrite, although this fact is different from each other in terms of authorship and expression, but it speaks in the content and has one aim, the advice of the other and preach.

\section{The text and its meaning}

If we go back to each text of the concepts and each of the words dealt with in daily life believes that each has a long and long history and its beginning dates back to some of them and that researchers and writers who researched on the book (Vidya) to serve religion and save the effects of debate and controversy at the time so that Some thought it was a source of inspiration and a spring, and some said it was not, but the events and creativity of man. After the Indians interest in the meaning became the interest of Greek philosophers and Plato believed that there is a relationship between form and meaning other than Aristotle, where he believed that this relationship is subjective.(12)

It seems that there are different opinions about this and from which these concepts are mentioned, and therefore some of them believe that the term Sima Nitex was derived from Sema, which refers to the sign or symbol, and that some terms refer as the first word to (Michelle Brill) who He used it in 1883.

This means that the search in the meaning of science cares and searches for meaning and content and a branch of the terminological and that the main requirement in this section the presence of symbols and signs in order to carry meaning and content and it is one of the top of the terminological search, It is not here yet the definition of a comprehensive and inhibited and accurate is the content and meaning so that it contains all sides and aspects and therefore identify and define science in the meaning and search for it is not easy and easy because it has wide and confusing dimensions and therefore knew linguists and people of industry in different terms, and we show here some of them(13) 


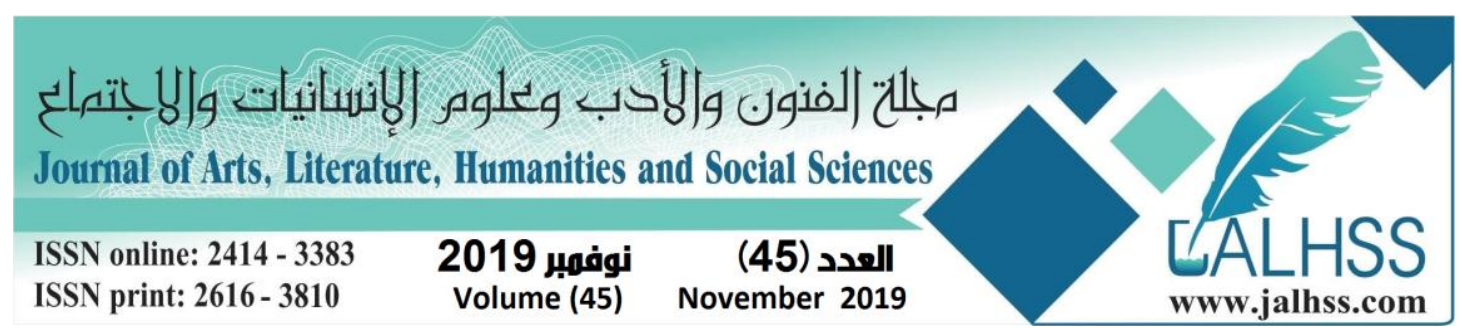

Orhman al-Haj Kharaf says: (Knowledge of the concept is a major section in linguistics and all issues and looking for them any issues that relate to the meaning and content. This means that knowledge of the meaning searches from these topics that relate to the meaning and moral intent or knowledge of the meaning is the study of meaning and tries to distance from these topics, Knowing meaning is a science that talks about theories of meaning or science that searches for the necessary conditions in the symbols so that it can take meaning. This means that those who know the meaning and content do not deal with some kind of meaning, but delve deeper into the search for all other branches. Science that searches for the meaning of words or this linguistic section that searches for the theory of meaning and concept from all of the above definitions shows us that knowledge of the meaning of science searches for the meaning and theories and study them.(14)

From here it turns out that a general definition of the meaning agreed upon by all linguists is not an easy thing. Some of these views, Tolman believes: (meaning that this is a straight relationship that exists between the sense and the word or between the word and the meaning and thus be between the word and the image of its own so that the word and the sense is born from one to the other and thus the relationship is two parties and custom (Bloom Field) Where he says: (meaning is the position that does There is a linguistic event with this interaction or this answer that is in the linguistic incident that the hearing person has).

This definition is ethically seen as meaning based on excitement and answer and on this built. Versus also means meaning is a set of contextual relationships that are not clear but turbulent. Therefore, two of them distinguish it from the rest of the sensory, linguistic, original and descriptive meaning. To speak out and agree on the label of this thing and its meaning. According to this view, it is said in Ibn Bani Ghanam's case that all people know their meanings and what they are used for, what the community agreement has passed if the community agrees on them.
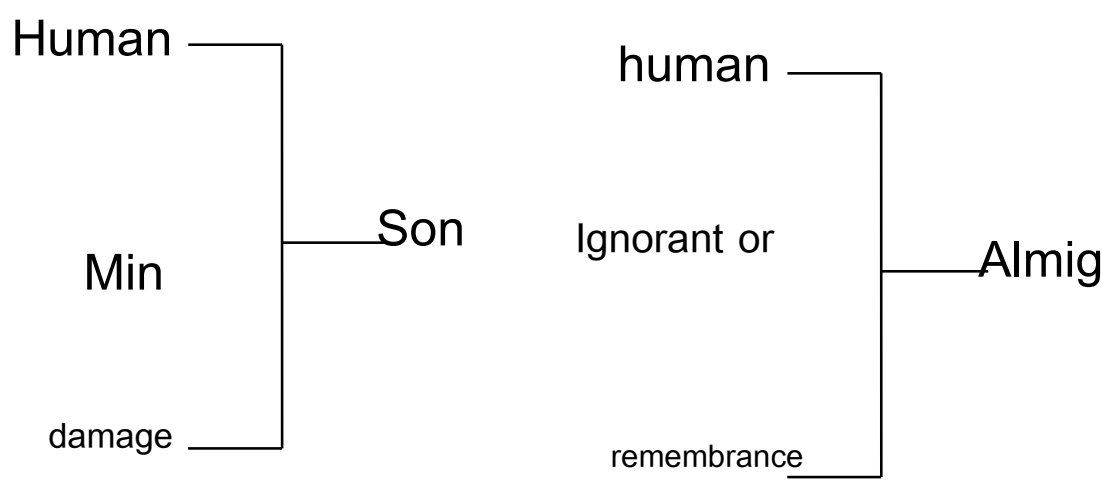


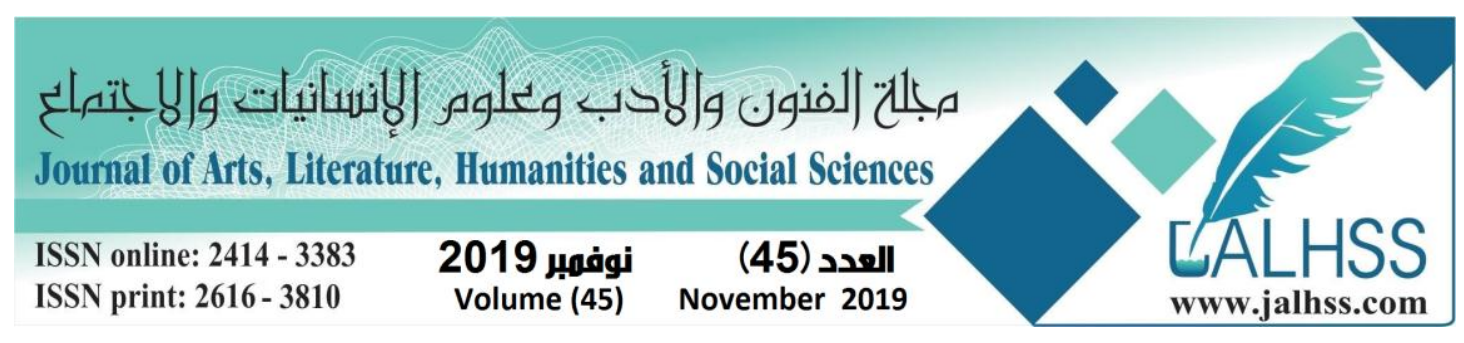

This theory and thought goes back to the seventeenth century. The English philosopher says his use of the word should directly represent thought. According to this consideration, the word meaning has this group and this imaginary image and the proportion that is related between them and express and reveal in writing or uttered, This means the sensual or imaginary meaning unlike all other meanings as it is theoretical and especially where it is easily compared with the monument of other linguistic levels, especially monument of phrases and sentences and this works on the basis of these foundations, The distinctive formal basis of this type is that a voice is defined as a negative or positive voice, as is clear in this example. These peculiarities (human hee rush, dhikr meaning lump into pieces composed this basis of small pieces swallow us to large terms or vice versa give us this power enables us to deviate the linguistic meaning into small pieces.(15)

This type of meaning is immutable, changing from one person to another or a group to the other group. For example, if there is a metric when a person is around something that may not be true, it can be changed. The sensual meaning of the word includes a kind of meaning such as the Jewish word is a person who is a convert to Moses. This is the sensuous meaning of the word, but the word stingy, cowardly, greedy is the necessary meaning for the Jewish person these necessary meanings or That sheep is an animal (Hee Rush), commend Meaning tangibly-kun ... etc.

This means the use of the word or word in a non-linguistic or positive, and it is not a requirement that each linguist in the original meaning, although this type of meaning does not amount to the amount of sensory meaning. But many people of the language and tongue believe that this complementary to the meaning of the necessary or metaphorical meaning, but contrary to the sensory or imaginary sense changes the sense of the person, time and group. Mixed with the feeling and thought of the speaker and therefore does not relate to the dictionary, but the community carried another meaning such as the meaning of sensory and imaginary (man) in addition to the three forms of human male ... etc., does not indicate another meaning, but with the meaning loaded other than these three forms and features The meaning of honesty and acceptable deal and decent position to upload these meanings on them. This includes all the meanings that have been added to the spoken or sensory meaning and this is one of the variables depending on the place, society and age. This kind of meaning is not recorded in the dictionaries because it is in an infinite continuous change and has no distinctive signs.(16)

The characteristics of meaning loaded or figuratively:

1 - sometimes mixed with sensory meaning.

2 - in a permanent change because it advances have an open end.

3 - The first is the order of measurement a lot or a little. 


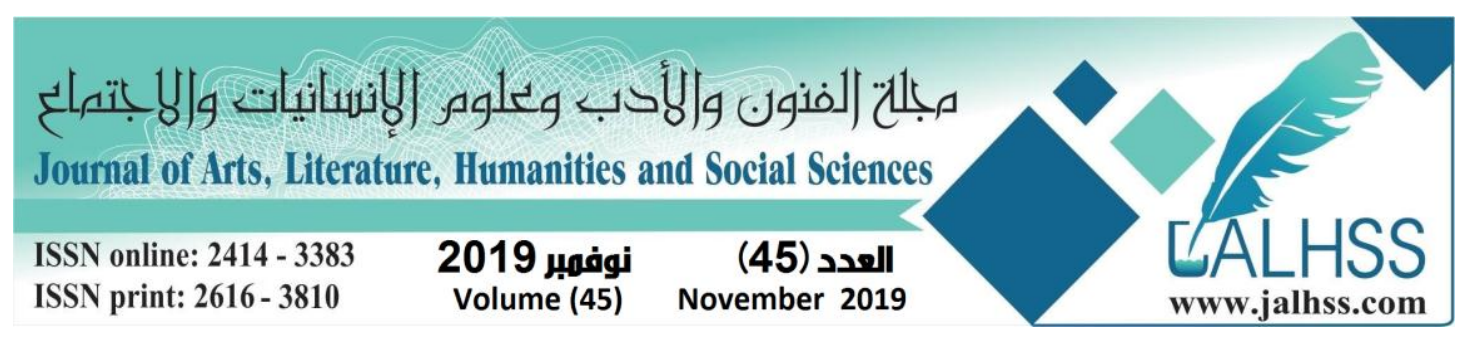

4. The good place, age and society are changing.

5. It is not explained by its form.

Types of loaded or figurative meanings:

1. Media sense: This type of meanings of the most important meanings loaded with meaning as well as sensory used during everyday life and Altjarbah positively or negatively whether or psychologically.

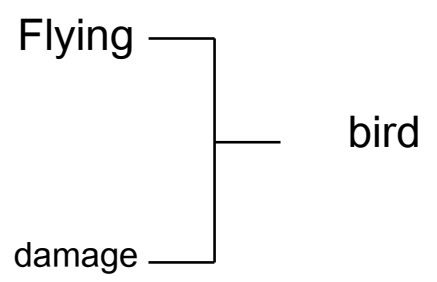

This type of bird in Kurdish society is interpreted by flying and ruin means a reference to this, but not a requirement to be interpreted so in all other societies and this means that the meaning differs from one community to another community, as this type of birds indicates the meaning of optimism in English society, Or cow, for example, refers to the abdomen, laziness or sloth.(17)

This kind of animal in Kurdish society indicates the frequent eating and non-work and Alex sense of the use of those people who use it or who are related to this spot in this time and this determines to us a number of levels and levels of the tongue, such as culture and status and rank and the relationship between the speaker and the listener and this meaning gives us knowledge And knowledge about the speaker and the listener and this meaning gives us knowledge and knowledge about the speaker and the listener in terms of social status and academic and scientific level and the tongue level used by whether he speaks like logistic or literary, such as the use of the word mother and father. These words are used by the Chinese person for those with knowledge and prestige means the use of a person with knowledge and status, etc.

This kind of meaning includes words that have two meanings. We can say that the loaded meaning occurs during the specific sensory meaning and used elsewhere so that when we hear one we remember the other.

This means including those words that have two meanings or that refer to two meanings, but one meaning dominates the other when we hear the word directly come back non-stop and think remember the meaning: and e.

Accompanying the meaning or accompanying meaning This type of meaning comes with the relationship to the other word so that the accompanying arises between the two words by attracting each other such as (light) often accompany the color or eye 

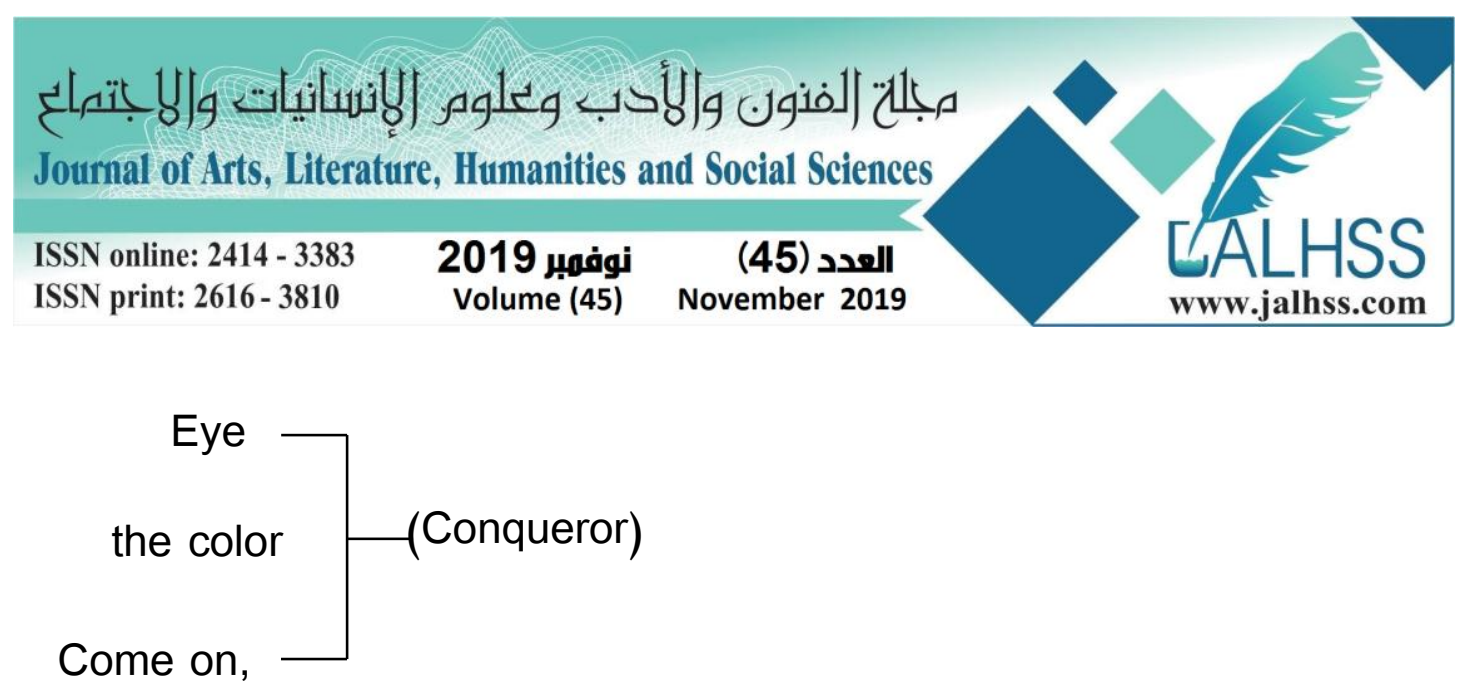

Or the sound of a lion, dog or donkey.(18)

We can say this meaning occurs during or the result of a word accompanying with another word or in other words that there are two words, so frequent use together became necessary words so that one keeps on the other, this kind of meaning relates to the intent of the speaker when the speaker speaks and expresses the word to indicate interest It is clear from this definition that the speaker through the organization of the destination informs the other and it is a choice between presenting one or the other or taken so as to confirm what is most important for him, such as (reputation of the news from the unemployed Siraj free of dots), in this fact that the wise Emphasized (reputation) In the second fact Hakim stressed (the Raj) and make it the main subject Mona (prevention) relates to the relationship of the language situation, but the problem of the choice of language situation that he sees good to inform our intent among these situations allowed by the language and this means that the meaning of the subject changes by describing the materials within the sentence in other words that the meaning of the other and their organization The objective meaning affects an influential meaning, ie the psychological meaning, This kind of meaning is attached to the psychological state of these people who use it and this indicates the meaning created by a person in exchange for this word used by them, this meaning shows the feeling of the speaker and his passion for exclamation and denial such as regret and affection, etc., and mixed with the sensory meaning.

Another view of the meaning of psychological (influence) is that the meaning of psychological meaning of subjective and personal and unique to the speaker or speaker what this means that this is not general and this meaning appears in the normal talk the day he used or at the time of writing the book or poets versus this word that has this concept, If this meaning enters personal or personal status and often appears when poets and writers especially at the time of the development of poetry or anecdote or any other topic.

Nali says: (Kindle on the back of the fire), this fact here commented on the intent of the speaker means he knows used the fullest meaning came whether he meant by his side or by his calmness or patience any patience of the person new to this truth.(19)

\section{The relationship of meaning in words:}

A relationship that links a word to another word on the side of meaning, meaning that each word used in the language in terms of meaning has two relationships with other 


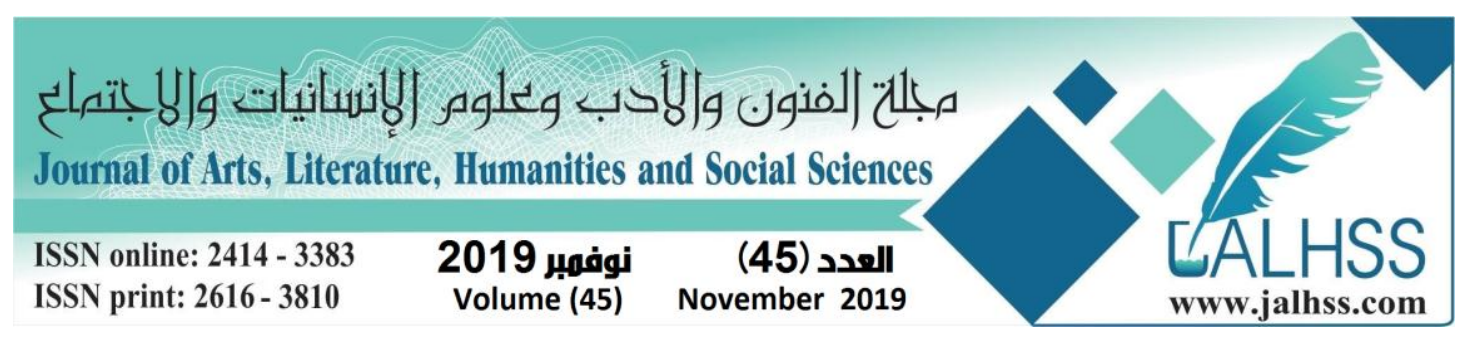

words:

Horizontal relationship: It is a relationship that exists between the words and appearance and harmony with each other within the boundaries of the sentence in a horizontal and this means any word added or included in any word or phrase of the relationship at the time of the coming together at the time of the appearance of words gets this annexation. Such as their relationship together, the relationship of harmony, the harmony between words within a sentence, etc.

In other words, we can say is the relationship between the words at the time of writing the effect of the words listed each other so that each of them affects the previous or subsequent sentence such as (flew the child, or cried bird) This relationship is not valid and unacceptable, because aviation supplies the bird The crying of the child's supplies, if this narrative is not true, but when we say the child cried and the bird flew, the relationship between the adjective and the descriptor is true. Linguistic Relationship Exist between the words and the expression of the word in other words in the same environment on the vertical case without work in wholesale and without changing the meaning, Such as: Azad intelligent student the word (intelligent) has to do with being rational or brave if diligent or quiet ... etc and also includes the relationship between words ... etc.(20)

This means that this relationship exists between words that appear from existing materials and non-existent materials. Another example (sold Hewa and rose) from here that the word (Hewa) has a horizontal or vertical relationship with each defect Azad Karwan Chelan and also that the word (Rose) has a vertical relationship with each of (book, booklet, pen ... etc), and that The word (sold) has a relationship with both (reap, and dedicate ... etc).

The relationship of words at the word level is divided into these sections.

First: Synonym: The words have the same meaning or synonym if they mean one.

Synonym when the linguist Muhammad known Fattah knew two definitions one of them is two or more words that indicate or denote the meaning of one or the same meaning, but used one or one of them in the place of the other in conversational and speaking such as tact and beautiful.

Balhar says: There are both giving one meaning and are called synonyms. Cruz also says the synonym is the relationship between words provided that these words are in the moral qualities originally synonyms, but some cases are different in the attributes lateral, Another view is that what is meant is words that are synonymous with concept and meaning, but in form and writing are different. All words taken are, for example, one meaning, but they are different in form and image. It has distinctive features and can be used instead of other.

\section{Synonym types:}

1- full synonym (full): This occurs if there are two or more words and the first have the same meaning and that the linguists do not feel any difference between them or between them so that they have full freedom to deliberate as they want it like Bint Nazif green. 


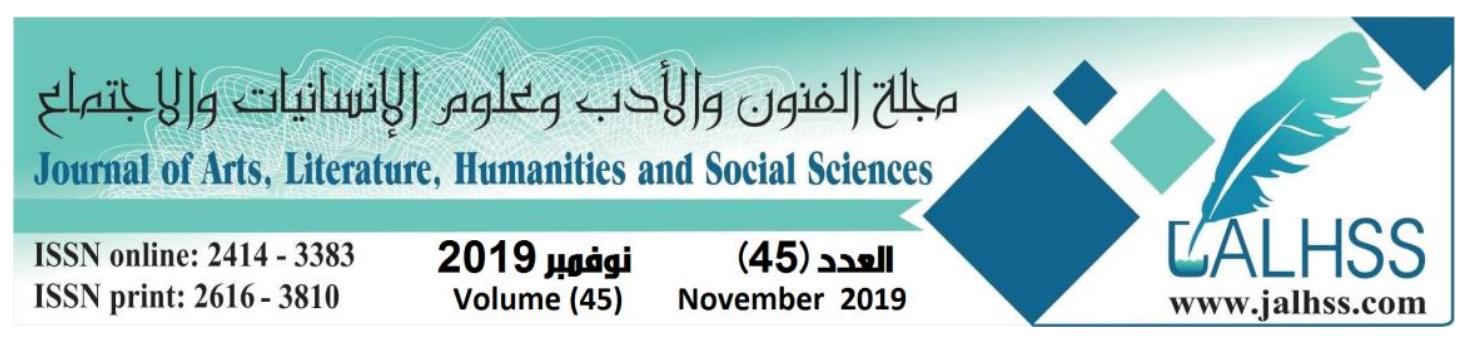

2 -incomplete synonym: This type of synonym is the convergence of intent or the convergence of the meanings of the words, so that the imbalance of each other in place and in the Aswan, but do not fit in another circumstance.

3-synonym of the face: This type expected or appears from the words that are in the same convergence, but each word is different from another in an important adjective.

Such as: II coverage. Coverage is the relationship between the two words in such a way that the meaning of a broad word can include the other word. Thus, inclusiveness is close to synonym because the universal word can include the special word.

Such as peacocks, pigeons, hippopotamus, opp (bird), or rose tree plant ... etc versus (tree).(21)

\section{Types of inclusiveness:}

Straight mass: This is the universality that connects an important member between them, such as yellow, green, red, etc.

Unequal universality: A totalitarianism that does not link them with strength and strength. But the relationship between them Choli. And collect them, such as: Gift: pen, perfume, watch.

Inclusiveness

It is comprehensive, each of which covers the preceding such as: seconds, minutes, hour, day, week, month, year.

Multi-meaning:

A common word is a word that has more than one meaning but its meanings originally converge and are written in the dictionary with a single word.

The common is that the signifier is more than connoted, that ties them.

He also looks for the common in present and historical terms only.

Linguists such as Palmehr Legg-Frinken Mordman believe that the first form in the joint has different meanings.

From all definitions and opinions shows us that the common term for words that have more than one meaning in the language of this kind our Kurdish language is rich, such as Ahar or a day called on Fridays, the day means the sun ... etc.

Or the moon of the months of the year, the moon in the sky

Such as pain $=$ soreness..

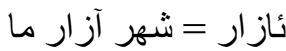

Mar comes in the sense of money. It comes in the sense of living, we see here that all definitions make sure that the homogeneous words are united in the origin but their meaning is different means that in terms of meaning spaced and does not have any relationship.

Types of alliteration(هاوبير ى)

Anaphylaxis is a word or words whose letters are the same but in different conversations and affect the force of its texts.(22)

Full anagrams: words that are united in writing and pronunciation.

The growth of Tach comes in the sense of food, and comes in the sense of millstone. 


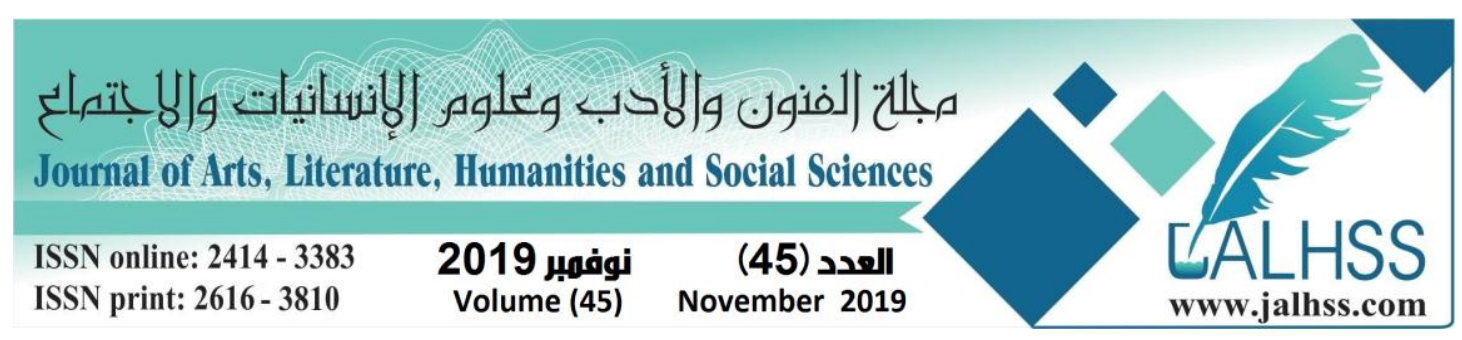

Cher comes in the sense of milk, and comes in the sense of the sword.

Contradiction It is clear that in each language in opposing quantities imagine a relationship between them, and this relationship exists between the opposing words of this language and most linguists agree on this definition that the opposite of the two words between them in the opposite meaning in the sense of life and death, large and small correct and bitter and sweet error and say Sazan certain that Contradiction means that the two opposing words which have the opposite meaning, and that the opposite is the case of the Hadith, there is the relationship between the word and the object or the relationship between the two persons, in which the idea of the opposite and the concept from all these definitions shows us that the opposite includes these two words which are in the meanings. Two different meanings and their meaning are opposing and their meaning stands in the face of the other but envisages a relationship between meaning and form, such as a good note when feminine feminine bar bar rum hot hee poorer state rich rich. سار بار كه رم هه زارر فقير دولنمةتندي

Types of contrast:
1. Offense).
2. (inversion).
3. (variance).

First: Linguistic Meaning:

The most important meaning is part of the linguistic meaning of the word because the words are used in the linguistic sense and they all know why they used them. Mattresses status to another language, especially the situation (Volognoji) and sentences or phrases.(23)

Also, this meaning exists in the Kurdish reality, as shown in the following examples:

Dismantling Maine horse weapon weighs women in the hands of their owners.

We see in this fact that words have a clear and apparent meaning used in a linguistic sense so that it is easy to understand easily between the speaker and the addressee and that their meaning is apparent without resorting to the interpretation of the words that exist in truth. Operative or reasonable and added to the sense of concrete and does not identify easily and does not depend on it because the masses have agreed on its meaning and changes according to place, age and society.

Mohammed Marouf Fattah says: (It does not have a limited limit and closed contrary to the meaning of the concrete and the sides where they are open and we can say that most of the old Kurdish truth falls within the framework of the metaphor or loaded

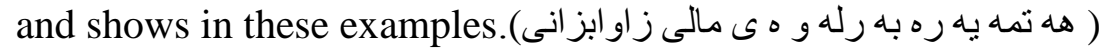

I mean, do not dance before knowing between the bride, from here is not intended to dance, but wanted the other sense of pregnancy or figuratively, but intended to not interfere with the rights of others and do not rush before you understand the thing and work until you clear these things

(تاس به زه نكى خؤى نها نى دانارزى). 


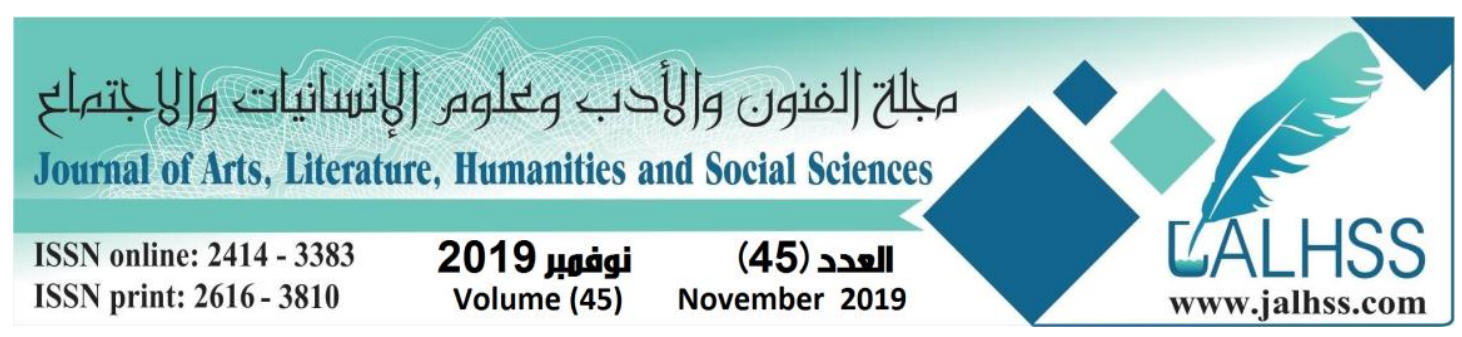

It means that iron with his rust wears out.

This fact indicates that every bloc, group, and sect cannot be controlled by the enemy unless they are different and scattered among themselves.

Types of metaphor:

\section{The first is the media meaning in the old truth:}

This type of meaning is presented with the perceived and varies from one society to another, Because this is a good perception of societies and this is related to the spending of societies, where in some words an ugly signal and there is in contrast to the contrary and this kind of meaning in the Kurdish society is clear and especially in the Kurdish reality such examples the following(24)

(هاوري خر اب وه ك قه له ره ش واية)

Means that bad comrade is like a crow.

When we interpret this fact in terms of meaning, we see that the word Ge has rs (crow) that the meaning of ugly added to it is a bird free of interest, but the harm and harmful and can indicate this bird has a meaning other than the meaning we have in another society.

Or tell another truth:

The pork dipped and the tears from his mouse mouth.

$$
\text { مشك كونى لة بن لوتى بنز از كردبوةوة }
$$

Thus, this fact also contained a bad meaning because both the word pig and the mouse in Kurdish society are considered ominous and unpopular, taboo and malicious animals.

But they can be halal, sacred and useful.

Second: Useful meaning:

This meaning relates to how people use the language and tongue between the speaker and the listener according to the status and social rank and according to the place and level of education and the amount of progress of this language.This pattern includes all these meanings that give us knowledge and knowledge of the speaker and social and academic rank and give us knowledge of work and craft and so on.

As shown by this fact such as:

$$
\text { مالي ير لله زانان ج ئاو نيه لله كونان. }
$$

If we look at these two facts in terms of meaning we see that their meaning is the same but they are different in terms of expression ...

Third: the meaning of accompanying in the old truth This meaning is obtained by accompanying the word for another word means that there are two words not often used together become two companions to the syndromes and this means that the word as a result of their income together and repeat them together Reflected and feel so.

هةر مو خره به ك ئاونية هنر مو جنر اويك جاونيه)

Not every sound, the sound of water and not every weaving means a bowl.In this fact, both the word water and the sound have a companion because they come together, or 


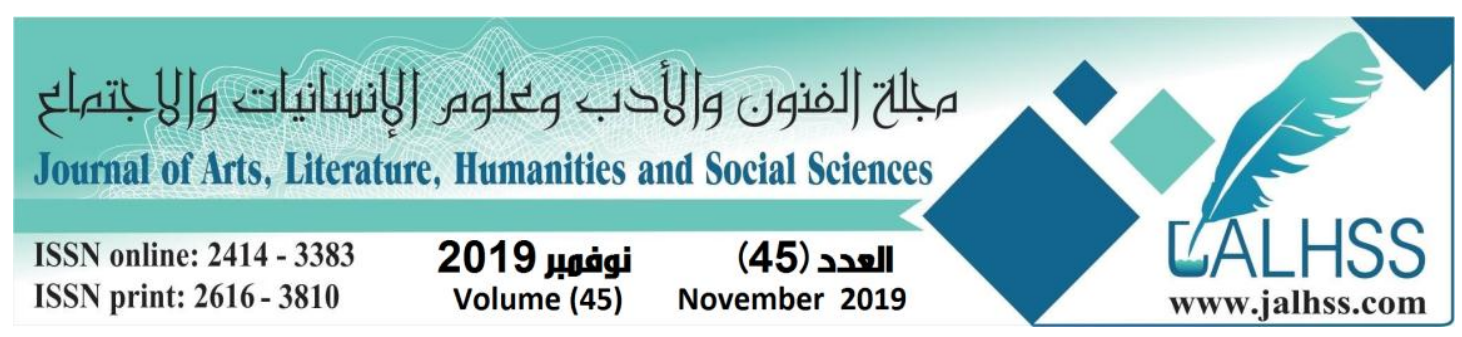

not every yellow is said to be gold.In this fact, too, the word yellow and gold have both. Or it is said that the fox is plotting and the chicken screams.

$$
\text { ئيس شيره زه نالى نه خور يتكرد ديو نار وات }
$$

It means that work like a donkey does not go until the market and work a lion when it began to become a fox and so in these two facts have one meaning we can use one place in the other and in these words give the same destination. The second is inclusiveness in the old truth. This means that a word in terms of meaning lies and is grouped under the general word.

شير وتير له به ك ده سون.

I mean, each of which limits his sword and ranks, if we manage in fact loan: that both the word Sher (sword) and Teer (nobility) are gathered under the shadow or dark general word is as (peace).

ئه ربه جه ك ما هـ له به ياره.

War means peace and trade with money. Hence, the word arms includes the elements of what we have mentioned that are used, such as weapons in war and fighting.

The same wing flies with his wings and man flies with his friend. The word wings are gathered under special words, which is gathered under his umbrella a set of special words, ie the bird. It is said: Kills chickens and takes into account the chicks.

Third: the verbal joint:

The participant is a linguistic word in which a group of different meanings mean each word means more than one meaning that the word must be original but give different meanings. In order to determine the relationship of the subscriber in the old truth we offer a set of examples, ripened fruit if we do not rotting this fact used in the sense if it is time to do what should not be postponed but must work and implement otherwise or weaken and spoil and then does not get his place and this fact also used In other words, what is meant is that if the girl near the time of her marriage should marry, otherwise the sun is absent and the sentence wants her voice her enemy.

I mean if the uniqueness of the sentence and reveal itself does not catch one, in other words if the man did not use his tongue badly and did not say outrageous words in quiet and comfort and did not make him a problem.

Anagrams in the Old Truth(25)

Anaphylaxis occurs in words that are in form, form and elements, but in terms of meaning are different and uttered by one word and expression, but their meaning restores each other and there is no relationship between them. In other words, anagrams are two or more words and between them or some kind of subscription but both The two words in the meaning are different and also the homogeneous words came from different historical sources, and in order to clarify the anagrams in the old truth we offer a set of idealism that was not in the sword sharp war if we manage in this fact shows us that the war types of war, nomadic war, war in peace and in Kurdish (Inch) have a gloss more milk sword and other weapons.(26) 


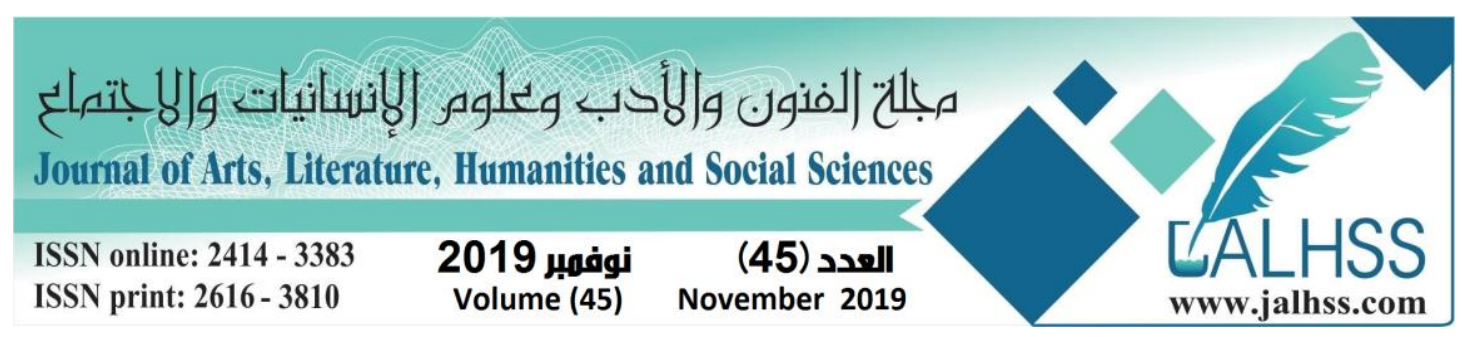

It is intended to leave meaning and leave the other meaning indicated by the word (do not dig the well with a needle).

In Kurdish, the word "bear" refers to the meaning of the real well and also refers to human thought.(27)

Moral Contradiction in the Old Truth:

This relationship appears if there are two words with different meanings and each one agrees in terms of meaning in the face of each other in which the opposite moral to clarify this kind found in the old truth. She graduated from her place to speak well, Shah patronized by Mar Dar.

It means that the judiciary and the living truth is to be with the stick, and between these two facts is counter-moral as the first is intended to use a soft pattern but in the second that is intended to use violence against the enemy or in other words that they are meant state of war and peace.

It means that each of his hair grew a year, these two words are contrary in terms of meaning because the first is the statement of the ignorant person who does not understand, but what is meant in the second is that the person is skilled, smart, intelligent and brave.

\section{Conclusion}

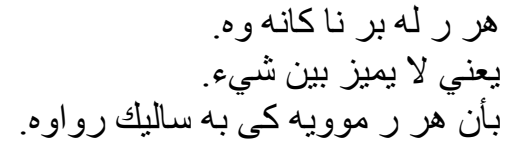

In the results or results:

We have reached during this research and this study the following results:

1 - that the old truth has a contagious template and many of them a brief and short sentence and carried many meanings means a little pronunciation of a lot of meaning and this indicates that the language goes to ease because in fact many meanings in the shortest sentence and phrase.

2 - Kurdish truth can be a campaign composed because many of its meaning is not consistent with the meaning of words.

3 - We can say that the fact that the Kurdish truth has become a reason to enrich our Kurdish language and enriched a lot of our language.

4. Meaning has a great role in the old truth because it is not often used in its original destination but carries in it another meaning and used in it.

5. Although the language of truth is easy and simple in the picture, but a short term with a lot of content and accurate and deep in terms of meaning.

6. The old truth is not specific to the borders of a State but transcends borders and has become universal.

7. The old truth is not special as it has been shown above.

8 - because the old truth followed within the community and therefore reflected in the life of society in many areas of life, including the economic, political, religious, customs, traditions ... etc.. 


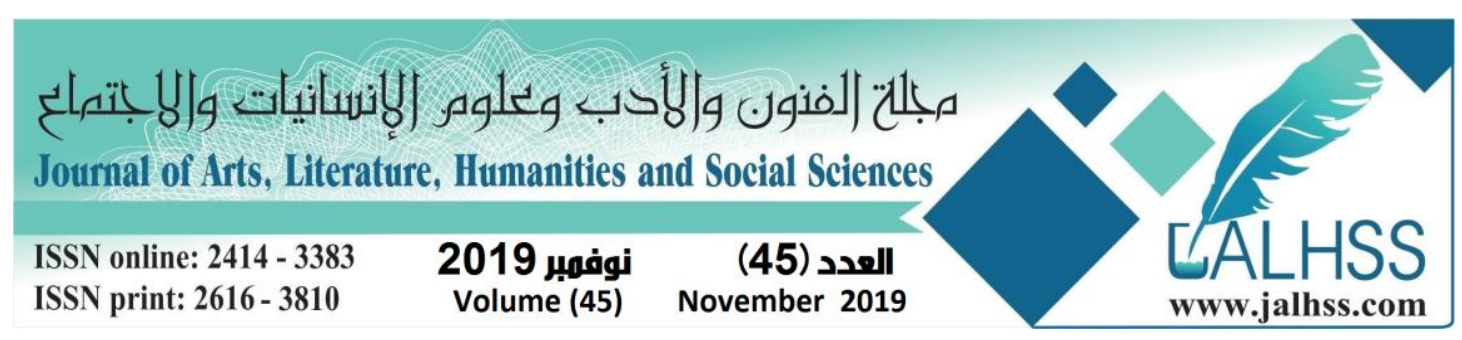

\section{References}

1. Narian S. Aziz (2008) Kurdish diplomatic language, MA paper. College of education. Baghdad University.

2. Idris A. Omar (2014) Not to forget, first. 3.

3. Bekhal A. Sahid (1989) word semantics, college of arts, Salahaddin University.

4. Yarubn O. Mustafa (2009) Meaning and translation, first edition, Hawler

5. Talib H. Ali (2011) Semantics, topics about word semantics, first edition, Hawler.

6. Dara H. Mhamad (2010), Semantics (some aspects of the Kurdish Semantics and Pragmatics) first edition, Zheer Publications, Silemany.

7. Dyar A. Kamal (2010) Kurdish political discourse in sense of pre_forecasting, PHD paper, Salahaddin University.

8. Sazan R. Moien (2005) Meaning and surroundings, MA paper, College of education, Salahaddin University.

9. Saeed A. Hirrut (2010) Proverbs, second edition, Aras organization of Publications, Hawler.

10. Shukria R. Ibrahim (1984) Kurdish proverbs and sayings, (the core of the literature thought)

11. Shukria R. Ibrahim (1984) Kurdish folk literature, second edition, Salahaddin University Publications, Hawler.

12. Shekh Muhamad khal (2007) Proverbs, fourth edition, Shivan publications house, Silemany.

13. Sabah M. Ali (2009) the reflection of some of the semantics aspects, first edition, Aras organization of publications, Hawler.

14. Abdulwahid M. Dizayi (2014) the semantics of words and sentences, third edition.

15. Abdulwahid M. Dizayi (2009) Semantics, Eeasteran publications hous.

16. Abdulwahid M. Dizayi (2010) words and sentences semantics, first edition, Eastern publications house, Hawler.

17. Izaddin M. Rasul (1979) Kurdish folk literature, second edition, Silemany .

18. Izaddin M. Rasul (2010)Kurdish folk literature, third edition, Hawler.

19. Ali M. Sharzuri (2010) Kurdish Proverbs, second edition, Silemany.

20. Ali Rukhzady (2011) (Kurdish proverbs and sayings), third edition.

21. Omar Sh. Debshtaky (1980) Kurdish proverbs, third edition, Kurdish publications and culture organization, Baghdad.

22. Claud G. Rimo (2009) Semantics, first edition, Ministry of education publications house, Hawler, translated by Yosuf Sh. Sahid

23. Kurush Sanawy (2009) some aspects of Semantics, first edition,Hawler, Ministry of education publication's house.

24. Karim Sharaza(1984) enemies and friends and their reflection in the Kurdish proverbs, culture discourse.

25. Muhamad M. Fatah (2011) Linguistics, third edition, Hawler.

26. Muhamad M. Yonus (2010) a starter for semantics and Pragmatics, first edition, Minara publication's house, Hawler.

27. Yasin H. Goran (2006) Proverbs and stories, Hawler. 